\title{
Thermal methods for measuring the sap flow of common camellia
}

\begin{abstract}
Introduction: Hardy plants can maintain their normal physiological metabolism in cold winter and against the cold weather by regulating themselves. The physiological knowledge alone cannot justify the cold resistance of plants. Norbert Wiener has proposed in Cybernetics that life is also a heat engine. So it can analyze the anticold mechanism of plants from the perspective of thermal response. Therefore, it is necessary to analyze the heat transfer process in plants and that with surroundings.

Methods: An open-top artificial climate plant growth chamber was built to measure the sap flow rate of ten year old Common Camellia plant by heat balance method, without considering the influence of water stress on temperature distribution and sap flow rate in the experiment. In addition, the experiment was taken in summer with strong illumination intensity and transpiration. The relationship between sap flow rate of Common Camellia stem and illumination intensity, air temperature and soil temperature were eventual established.

Conclusion: The sap flow rate of Common Camellia has the same diurnal variation with illumination intensity and air temperature, but the time lag for about $1 \sim 3$ hours. The sap flow rate in cloudy differs sharply with that in sunny, and the latter is twice the value of the former. The sap flow rate of Common Camellia both has an exponential relationship with air temperature and illumination intensity in measurement range. The sap flow rate of Common Camellia in summer is about $0.056-0.178 \mathrm{~g} / \mathrm{s}$. The sap flow rate has a "single peak" relationship with soil temperature within the temperature range for about $19.22 \sim 32.49^{\circ} \mathrm{C}$ and reaches the peak at $23.8^{\circ} \mathrm{C}$. Although the sap flow rate was influenced by the three factors of illumination intensity, air temperature and soil temperature, the influence of each parameter on the sap flow rate is different. Order from high to low is the air temperature $(0.554)$, illumination intensity $(0.338)$ and soil temperature $(0.343)$.
\end{abstract}

Keywords: sap flow, heat balance method, common camellia
Volume 2 Issue 2 - 2018

\author{
Xuan Xin, Wentao Zhang, Qingling Li \\ Mechanic and Electronic Engineering, Qingdao University of \\ Science \& Technology, China
}

Correspondence: Xuan Xin, Mechanic and Electronic Engineering, Qingdao University of Science \& Technology, Qingdao, 26606I, Shandong, China, Tel +86-0532-88956828, Email xinxuan081212@163.com

Received: December 28, 2017 | Published: April 02, 2018
Abbreviations: SPAC, soil plant atmosphere continuum; HPV, heat pulse velocity; THB, tissue heat; TDP, thermal diffusion method; SPSS, statistical package for the social science; HSP, heat shock protein.

\section{Introduction}

Hardy plants can maintain their normal physiological metabolism in cold winter and against the cold weather by regulating themselves. Around this natural phenomenon, a large number of researchers conducted researches on cold resistance of hardy plants and the mechanism of cold resistance respectively from the point of cell membrane structure and characteristics, physiological metabolism, growth environment stress and so on. However, the cold resistance of plants is the quantitative trait of micro-effect multifactor control, which has complex properties. So no convincing results have been obtained so far. Norbert Wiener has proposed in Cybernetics that: Life is first a heat engine. The energy conversion and utilization process of living organisms does not conform to Carnot Theorem for the temperature difference between living organisms and the surrounding environment is very small. ${ }^{1}$ Although the theory is aimed at human tissues, plants also have physiological metabolism in the process of growth and adapt to the surrounding environment. As an efficient open thermodynamic system, plants themselves are also a "heat engine", which has their own thermodynamic principle. Therefore, it can analyze the anti-cold mechanism of plants from the perspective of thermal response.

Plant is an effective intermediate between soil and atmosphere, and water is an important medium through SPAC (Soil-Plant-Atmosphere Continuum).In the process of plant growth and development, water plays an important role: it is an important component of plant cells, a reactive substance metabolism, biochemical reaction and mass transport medium. In addition, water has important ecological significance, such as the regulation of plant tissue temperature, improve the ecological climate. In order to quantitatively examine the effects of water change on plant physiology and ecological processes, the method of continuous measurement of sap flow rate is widely used by scientists. This study will has enormous values for thoroughly investigate the heat and mass transfer process inside plant, as well as the heating mass-exchange between plant and surrounding environment.

Based on different levels of measurement for stem sap flow rate, the methods can be divided into three types: SPAC system, forest level and single plant. ${ }^{2}$ Among them, the way of determining individual plants include weighing method, dry method, liquid flow rate method and so on. Weighing method is used to determine the large scale of high precision balance or lysimeter, very suitable for seedling. Sarcastic method belongs to destructive experiment, except for special occasions. A large number of researchers have noted that 
there is a good correlation between sap flow rate and transpiration rate, so sarcastic method is usually used to measure the rate of stem sap flow. Liquid flow rate method is flow velocity estimation of plant transpiration rate by liquid, which belong to nondestructive measurement, including the method of staining, radioactive isotope tracer and thermodynamics.

Thermal dynamics is experimental method of heat source as tracer source of plant stem flow measurement, heat generated in response to different degrees with different sap flow velocity of liquid, using sensors to record the heat change process, according to heat dissipation or by heating the stem, combined with empirical formula is derived the actual measurement of plant sap flow rate. Determination of flow in ensuring the integrity of plant under the condition of continuous monitoring of real-time. Accurately, the stem heat dynamics method has a wide range of applications owing to it's high time resolution. ${ }^{3}$ The method of thermal analysis for determining plant stem flow mainly includes Recorder (Heat Pulse Velocity, HPV), Balance (Tissue Heat, THB), thermal diffusion method (Thermal Dissipation Probe, TDP), Thermal deformation method (HFD) and so on. ${ }^{4}$ Heat balance method is widely used in the measurement of the flow rate of various plant stem due to its advantages, such as the characteristic of more mature theory and the convenient application, which .

Heat balance method was proposed by View and Ziegler in 1960, which is utilized for determining the liquid flow rate of herbaceous and woody plants. Kucera used heat balance method to measure transpiration rate in $1976 .{ }^{5}$ Groot and Grime pointed out that low transpiration rate should be considered under the error caused by thermal storage. ${ }^{6}$ Baker analyzed the heat balance method for measuring stem sap flow rate of basic theory in 1989 and established the mathematical model of heat conduction, the measurement error was calculated at the same time. ${ }^{7}$ Braun used weighing method to verify the heat balance measurement method of stem flow sensitivity and accuracy in 1999. With the in-depth study, flow meter is widely used in $1980 \mathrm{~s}$, as a commercial carrier-stem thermodynamic method. Since then, the research on plant transpiration water consumption was very widespread. The research on plant transpiration measurements in China begins in 90s, researchers gradually applied heat balance method to plant transpiration water consumption law. ${ }^{8}$ Professor Ritchie and Shen Xiuying from Shenyang Agricultural University used heat balance method for the determination of corn sap flow and transpiration rate in 1992. Luo Zhongling used the heat balance method and weighing method to determine the liquid flow rate and transpiration rate of wheat, value comparison between the two results showed that the error was no more than $1.4 \mathrm{~g} / \mathrm{h} .{ }^{9}$ To calibrate the plant stem flow sensor, Liu An provided a detailed experimental calibration method to obtain accurate plant stem based on thermal balance method for flow rate. ${ }^{10} \mathrm{Li}$ Shuang demonstrated the measurement accuracy by using heat balance method and error source. ${ }^{11}$

Stem heat balance method was used and experimental platform was built for measuring the sap flow of Common Camellia. It's well known that the Common Camellia physiological metabolism is weak, it's difficult to accurate determination of stem sap flow rate. In order to improve the accuracy of measurement, it's necessary to choose the appropriate situation to measure, such as strong illumination and sunshine (in summer). Illumination intensity, air temperature and soil environment were also measured in the process of experiment to comprehensive analysis the main factors affecting the Common Camellia stem sap flow rate.

\section{Materials and methods}

\section{Research object selection}

A well growth ten years old "Laoshan Common Camellia" was selected as research object with the height of $2.5 \mathrm{~m}$ and the stem diameter for about $44.6 \mathrm{~mm}$. Its optimum growth temperature is $18 \sim 25^{\circ} \mathrm{C}$ and it can resistant $-10^{\circ} \mathrm{C}$ low temperature. The experiment was carried out in Laoshan District of Qingdao city of Shandong province, which geographical position is $120^{\circ} 29^{\prime} \mathrm{E}, 36^{\circ} 07^{\prime} \mathrm{N}$. The mid latitude regions located in the warm temperate monsoon climate zone, rich light, heat resources are abundant. The annual average temperature is about $12.1^{\circ} \mathrm{C}$, the average summer day light is $6.47 \mathrm{~h}$.

\section{Experimental device}

An open-top artificial climate plant growth chamber was built $(2000 \mathrm{~mm}$ in length, $2000 \mathrm{~mm}$ in width and $4000 \mathrm{~mm}$ in height, covered by EVA plastic membrane with high light transmission. Top film can be closed or open), with soil temperature, soil humidity, air temperature, air humidity, wind speed, illumination intensity and other parameters adjustable. Ten year old Common Camellia plant was cultivated in the chamber. Experimental device as shown in Figure 1. The soil bed was cylindrical structure with $1600 \mathrm{~mm}$ in diameter and $500 \mathrm{~mm}$ high (stainless steel double bottom sealing sleeve). The sleeve gap was injected with water, which temperature can be adjusted by boiling water bath heating method. Then adjustable temperature distribution of soil bed can be obtained. In order to maintain the water temperature constant, the outer part of the stainless steel sleeve was additionally provided with an insulating cotton with a thickness of $30 \mathrm{~mm}$. Copper constantan thermocouples (phi 0.32) and Agilent data acquisition instrument (34972A) were used to measure and record the temperature of Common Camellia stem and soil. Illuminance meter (Mario AS823) with high accuracy was selected to measure the illumination intensity. Atmospheric temperature and relative humidity were acquired respectively by mercury thermometer and hygrometer (CYH-3605A). Hot wire anemometer (German AVH 545T) can determine the wind speed.
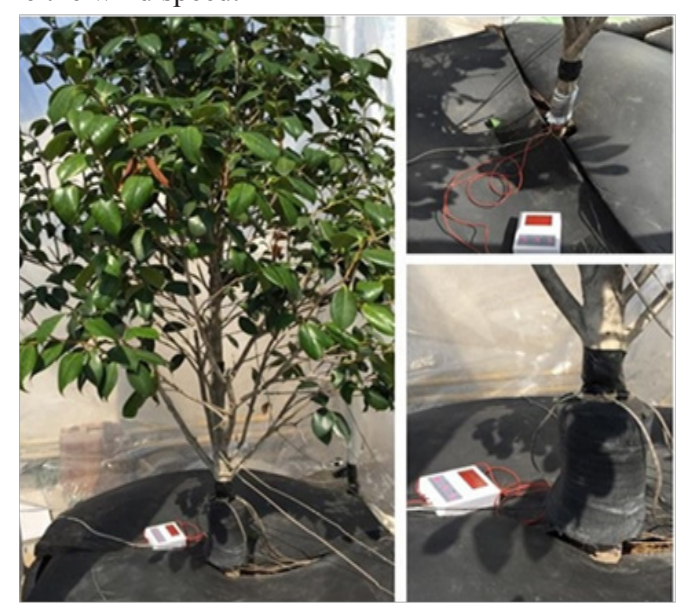

\section{Figure I Experimental apparatus.}

The major component of the experimental device comprises a flexible heating device, an insulating layer, a heating source and a temperature acquisition device. The heating device is equipped with silica gel flexible heating thermostatic switch (adjustable intelligent electronic temperature controller). The heater coil was placed in 
the steam and the external was fixed in the outer package of foam insulation layer by aluminum foil tape. The outer aluminum shell with PVC can barrier solar radiation effect. A diminutive $24 \mathrm{~V}$ lead-acid battery was selected as heating source with DC supply. The heat input power is $6 \mathrm{~W}$, adopting constant power heating mode.

Insulation material was coated around cylindrical soil bed to verify the critical diameter of insulation. When the outer diameter of the cylindrical soil bed is greater than or equal to the critical diameter, increasing thermal insulation layer thickness will make the quantity of heat reduced, otherwise not only no insulation effect, it will increase the heat dissipation. According to the formula, the outer diameter of the thermal insulation layer is the maximum value of the heat dissipation:

$d_{c r}=2 K_{c o} / \mathrm{h}=2 \times 0.037 \div(5 \sim 15) \times 10^{3} \mathrm{~mm}=2.96 \sim 14.8 \mathrm{~mm}$

Where, $h$ is the convective heat transfer coefficient of outer surface of thermal insulation layer, the air natural convection heat transfer coefficient is $5 \sim 25 \mathrm{~W} /\left(\mathrm{m}^{\circ}{ }^{\circ} \mathrm{C}\right)$. The stem diameter is $44.6 \mathrm{~mm}$, greater than critical diameter of insulation. So thermal insulation materials can play a role in preventing heat loss, foam insulation layer thickness of $30 \mathrm{~mm}$.

Throughout the experiment, the soil moisture was maintained at a suitable range, that is, without considering the effect of water stress

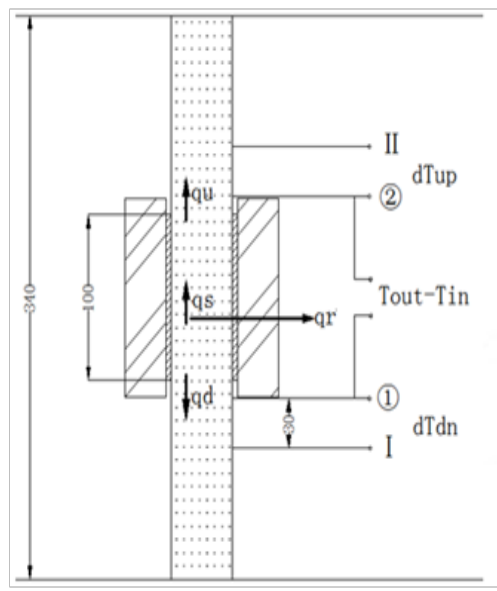

Figure $\mathbf{2}$ Schematic of sap velocity by thermal equilibrium method.

The lead-acid battery provides a constant current, and $P$ represents the input power used for heating the measured segment of stem. So the heat balance equation for the cadres can be indicated as:

$$
P=q_{u}+q_{d}+q_{r}+q_{f}
$$

Where $q_{u}$ and $q_{d}$ represent the heat dissipation in the vertical direction and vertical downward direction of the stem respectively. $q_{r}$ is the heat loss in radial direction. $q_{f}$ is the heat carried by the sap flow. Install the $T$ type thermocouples in the upper and lower parts of the measuring section and record the axial temperature gradient changes with 34972A Agilent data acquisition instrument, then the axial heat dissipation can be obtained. The axial heat conduction satisfies to the Fourier law:

$$
q_{u} / q_{d}=k_{s t} A(\mathrm{dt} / \mathrm{dy})
$$

Where $k_{s t}$ is the axial thermal conductivity of stem tissue, W/ $\left(\mathrm{m} \cdot{ }^{\circ} \mathrm{C}\right) . A$ is the stem cross-sectional area, $\mathrm{m}^{2} . \mathrm{dt} / \mathrm{dy}$ is the axial temperature gradient, ${ }^{\circ} \mathrm{C} / \mathrm{m}$ 。 on the flow rate. Need to pay attention to the following three issues in the course of the experiment:

Real-time monitoring the plant stem's temperature by using explicit transient temperature data acquisition instrument, repeated experiments and obtained the best heat balance setup time for subsequent experiment. Set the heating temperature and heating time in proper range to avoid long-time heat damage to plant tissue by using the intelligent electronic temperature controller that will affect the measurement accuracy.

Remove the heating device in time by the end of the experiment to dissipate heat to adverse effects of high temperature on plant growth and physiological processes.

\section{Experimental principle}

Heat balance method for the determination of plant sap flow rate was based on the principle of heat balance. The heating device was wrapped around the stems of plants and the heat transmits along the stem axial direction and radial direction. While at the same time, a part of heat flow will scatter with sap flow as a result of sap flow. The heat that the sap flow takes away can be calculated according to the balance between the heat input and heat loss in every direction. The measuring principle diagram was shown in Figure 2.

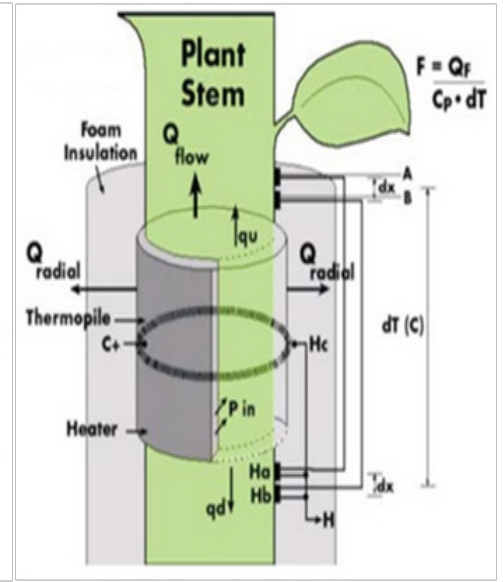

The radial temperature changes can also be measured by the radial arrangement of thermocouples and the heat dissipation meet single cylinder wall heat conduction heat flow equation:

$$
q_{r}=2 \pi k_{c o} L\left(\mathrm{t}_{\mathrm{i}}-\mathrm{t}_{0}\right) / \operatorname{In}\left(\mathrm{r}_{\mathrm{i}} / \mathrm{r}_{0}\right)
$$

$k_{c o}$ is the thermal conductivity of foam insulation, $\mathrm{W} /\left(\mathrm{m}^{\circ} \mathrm{C}\right) . L$ is the stem length of heating section, $m . t_{i}$ is the surface temperature of adiabatic layer ${ }^{\circ} \mathrm{C} . \mathrm{t}_{0}$ is the adiabatic layer temperature of the outside surface ${ }^{\circ} \mathrm{C} . r_{i}$ is the distance form inner surface to the center, m. $\mathrm{r}_{0}$ is the distance from outside surface of the insulation layer to the cente, $\mathrm{m}$. Assume that the Common Camellia stem has uniform structure in radial direction, and physiological metabolism does not change the flow conductivity of composition and microstructure:

$$
\dot{m}_{\text {sap }}=\left(\mathrm{P}-\mathrm{q}_{\mathrm{u}}-\mathrm{q}_{\mathrm{d}}-\mathrm{q}_{\mathrm{r}}\right) /\left[c_{p}\left(\mathrm{t}_{o}-\mathrm{t}_{\mathrm{i}}\right)\right]
$$

$\dot{m}_{\text {sap }}$ is the mass flow rate of the sap, $\mathrm{kg} / \mathrm{s} . c_{p}$ is the specific heat capacity of sap flow, $\mathrm{J} /\left(\mathrm{kg} \cdot{ }^{\circ} \mathrm{C}\right) . \mathrm{t}_{\mathrm{i}}$ is the temperature of the lower stem, ${ }^{\circ} \mathrm{C} . \mathrm{t}_{o}$ is the temperature of the upper stem, ${ }^{\circ} \mathrm{C}$. 
The heat capacity of the stem tissue cannot be ignored in the process of heating the Common Camellia stem owing to its low flow velocity. The performance is decreased gradually in the heat conduction process. So the heat dissipation of the tissue should be amendmented by adding the heat storage in tissue to the original thermal balance equation:

$$
q_{s}=c_{s t} V_{e} d t_{s t} / d \tau
$$

$c_{s t}$ is the specific heat of stem tissue, $\mathrm{J} /\left(\mathrm{kg} \cdot{ }^{\circ} \mathrm{C}\right) ; V_{e}$ is the effective volume of the heating section, $\mathrm{m}^{3} ; t_{s t}$ is the average temperature
${ }^{\circ} \mathrm{C} . \tau$ is heating time $\mathrm{s}$.

It has been proved that the measurement results may be overestimated because of heat storage of the stem. The revised formula for calculating the mass flow rate of the sap can be expressed as:

$$
\dot{m}_{\text {sap }}=\left(\mathrm{P}-\mathrm{q}_{\mathrm{u}}-\mathrm{q}_{\mathrm{d}}-\mathrm{q}_{\mathrm{r}}-\mathrm{q}_{\mathrm{s}}\right) /\left[c_{\text {sap }} \cdot\left(\mathrm{t}_{\mathrm{o}}-\mathrm{t}_{\mathrm{i}}\right)\right]
$$

Table 1 shows the measured values of the parameters used in the heat balance equation and the measuring methods and measuring instruments.

\begin{tabular}{|c|c|c|}
\hline Meanings & Numerical value & Obtain basis \\
\hline Stem axial thermal conductivity & $0.15 \mathrm{~W} /\left(\mathrm{m} \cdot{ }^{\circ} \mathrm{C}\right)$ & $\begin{array}{l}\text { KD2 Pro Thermal characteristic analyzer } \\
\text { measurement }\end{array}$ \\
\hline Thermal conductivity of foam insulation & $0.037 \mathrm{~W} /\left(\mathrm{m} \cdot{ }^{\circ} \mathrm{C}\right)$ & $\begin{array}{l}\text { KD2 Pro Thermal characteristic analyzer } \\
\text { measurement }\end{array}$ \\
\hline Stem specific heat & $2.8 \mathrm{KJ} /\left(\mathrm{kg} \cdot{ }^{\circ} \mathrm{C}\right)$ & DSC Differential scanning calorimetry \\
\hline Sap flow coefficient & $4.216 \mathrm{~W} /\left(\mathrm{m} \cdot{ }^{\circ} \mathrm{C}\right)$ & Based on the thermal conductivity of water \\
\hline Illumination intensity & $\sim$ & AR823+Split type illuminance meter \\
\hline Common Camellia stem cross-sectional area & $1.56 \times 10^{-3} \mathrm{~m}^{2}$ & Calculation of stem diameter \\
\hline
\end{tabular}

Table I Physical Parameters ${ }^{12}$

\section{Common Camellia stem sap flow rate determination}

The experiment of determining the sap flow rate of Common Camellia was conducted on August 6-11, 2015 in Laoshan District of Qingdao City. The plant grows under natural environment. The relationship between the sap flow rate with illumination intensity, air temperature, soil temperature and other factors will be supervised. The physiological metabolism of plant is exuberant during the time of 12:00-15:00 and higher sap flow velocity can be obtained. So in order to improve the measurement accuracy of sap flow rate, experiment was conducted during this time period. The thermal equilibrium time is set as $10 \sim 12 \mathrm{~min}$ after repeated measurement. The temperature changes of each temperature point were measured continuously and record a set of data every 10 minutes. Of course, the illumination intensity, air temperature, air humidity, soil humidity, wind speed and other parameters were also real-time monitoring simultaneously.

\section{Effect of illumination intensity on sap flow rate}

Solar radiation is the only source of energy needed for plant transpiration, and is also the initial driving force to change the rate of sap flow. The transpiration rate of plant was closely related to illumination intensity. The sap flow rate has the same varying tendency with illumination intensity during the experiment, as shown in Figure 3. Compared to Figure 2, some verdicts can be found:

The illumination intensity has tiny difference in two periods, so the sap flow rates are at close quarters. The sap flow rate of day 6-8 is about $0.056-0.171 \mathrm{~g} / \mathrm{s}$ (Figure $3 \mathrm{~A}$ ) and the day of 9-11 is about $0.071-0.178 \mathrm{~g} / \mathrm{s}$ (Figure 3B). The results are consistent with Nie Lishui's results. ${ }^{13}$

The sap flow rate of Common Camellia and illumination intensity have the same diurnal variation in sunny conditions, and flow rate increased with illumination intensity, but the time lag for about $1 \sim 3$ hours. It's concerned with the physiological metabolism and adaptability of plant.

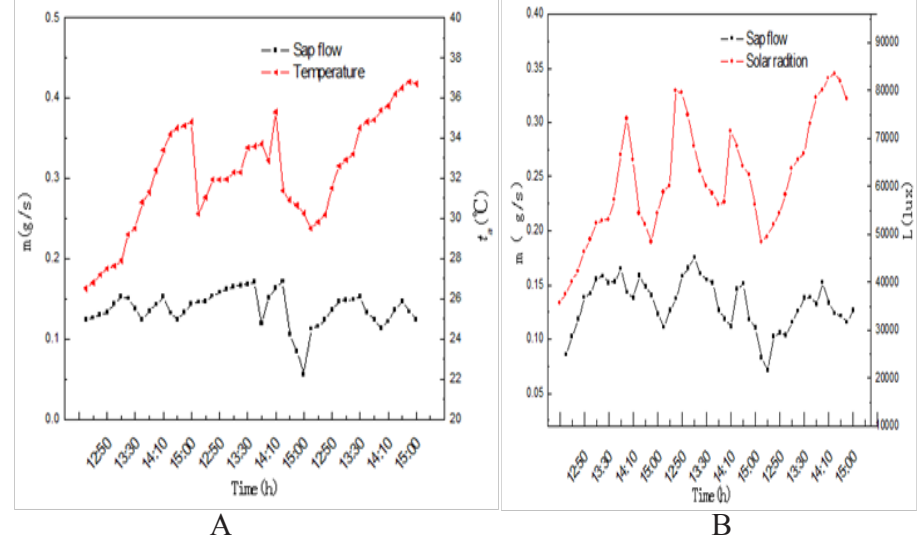

Figure 3 Daily variation of sap flow rate with solar radiation.

A. Day: 6-8 Time: $12: 00-15: 00$

B. Day:9-II Time: 12:00-15:00

For the August $7^{\text {th }}$ and August $10^{\text {th }}$ illumination intensity and sap flow rate showed a "multi peak curve" form because of cloudy weather. The sap flow rate in cloudy differs sharply with that in sunny, and the latter is twice the value of the former.

The sap flow rate of Common Camellia under different illumination intensity are plotted in Figure 4. The sap flow rate has exponential function with illumination intensity in the range of 35000 50000lux. The flow rate increase sharply with illumination intensity. But when the illumination intensity is higher than 50000lux, the sap flow rate fluctuates on a stable value. The main reason is that when the illumination intensity to the light saturation point, the stomata's of photosynthesis is closed. Respiration will be weakened because of water consumption, which indicated the sap flow rate remained stable

or slightly downward trend. The curve fitting was applied to attain proper relationship between sap flow rate and illumination intensity:

$$
m_{\text {sap }} \propto-20.405+0.00324\left[\left(10^{-0.00016 \mathrm{~L}}-1\right) /(-0.00016)\right]
$$


Formula (8) applicable to the illumination intensity range of 35600 66600 lux.

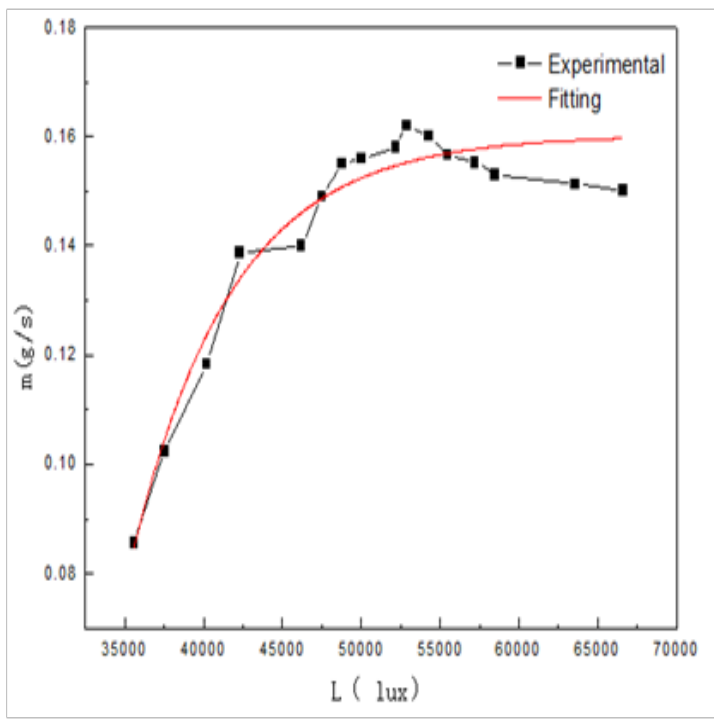

Figure 4 Variation of sap flow rate under different solar radiation.

\section{Effects of air temperature on sap flow rate}

Figure 5 shows the sap flow rate of Common Camellia varies with air temperature. In sunny weather, the sap flow rate increases with rising temperature in 12:00 13:00 time period. And the reason for that is the atmospheric water potential will reduce under high temperature, then the gradient of canopy atmosphere system increases that conducive to water escape from the canopy surface, both the transpiration rate and the flow rate increases. Where after, the air temperature continues rising (13:00-15:00), although the driving force aggrandizes, the sap flow resistance increase in proportion and the transpiration rate decreased. So the stem sap flow rate decreases with the rising air temperature. The measurement results can be found in Figure 5A \& 5B, the sap flow rate and the air temperature are in the same tendency, but compare to the air temperature, the sap flow rate changes more gently.

Figure 6 shows the sap flow rate under different air temperatures. The sap flow rate has an exponential relationship with temperature within the measurement range. Stomata conductance increases with temperature and the transpiration will intensify in turn, therefore, the sap flow rate will increase too. The variation tendency of sap flow rate with air temperature is similar to that with illumination intensity. Because the air temperature is relevant to illumination intensity, the temperature gradually increases with illumination intensity. So the illumination intensity is the direct factors influencing the sap flow rate. Over the course of the study, the moisture buffering capacities vary slightly for the selected tree is small enough relative to the whole research system. So the sap flow rate sensitive response to environmental factors. The curve fitting was applied to attain proper relationship between sap flow rate and air temperature:

$\dot{m}_{\text {sap }} \propto-168.6+46.071\left[\left(10^{-0.273 t_{a}}-1\right) /(-0.273)\right] \quad\left(R^{2}=0.95\right)$

Formula (9) applicable to the air temperature range of $29.5 \sim 38.1^{\circ} \mathrm{C}$.

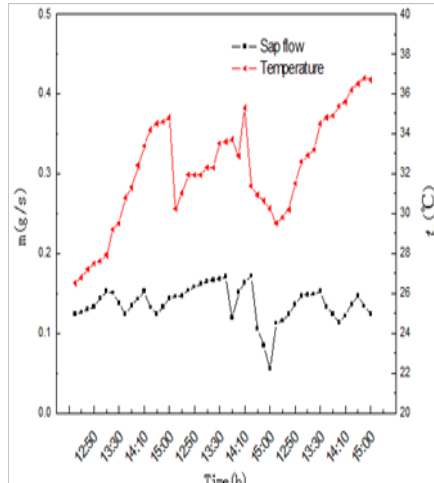

Time (h)

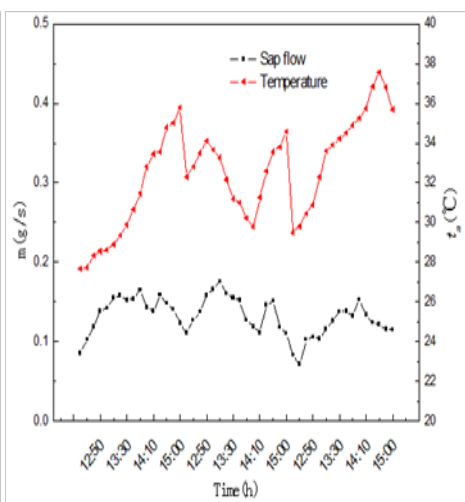

Figure 5 Daily variation of sap flow rate with air temperature.

A. 6 8 datel2:00 15:00

B. $\quad 9 \sim$ I I date $12: 00 \sim 15: 00$

Figure 6 Variation of sap flow rate under different air temperature.

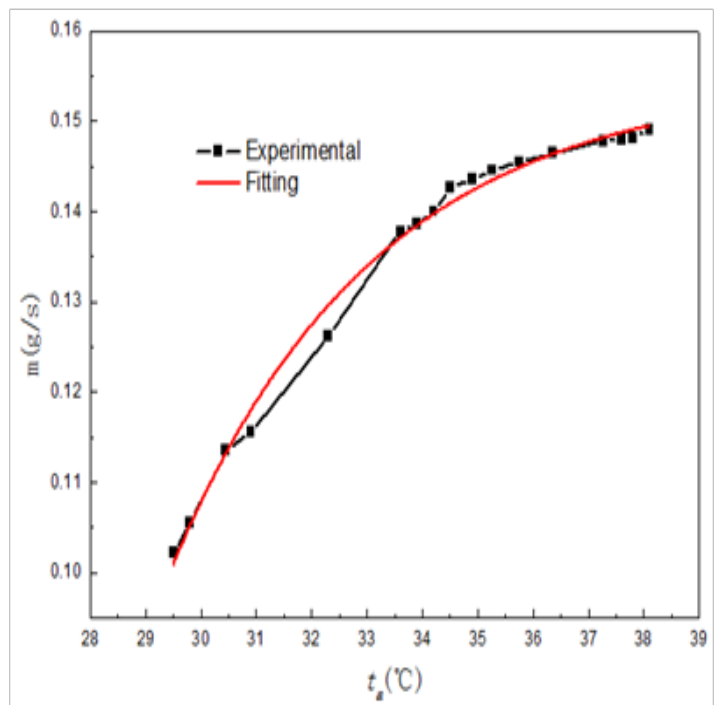

\section{Effects of soil temperature on sap flow rate}

There are many factors affecting plant transpiration rate, such as soil moisture, vapor pressure, solar radiation intensity, temperature, canopy type, leaf morphology, and so on. The main factors affecting the sap flow rate also changes with the continuous change of displacement in time and space. For example, Xu Junliang found that the sap flow rate of pine were mainly affected by soil water content in May and June, in July and August, that were significantly affected by meteorological factors, while in September and October, soil moisture or meteorological factors as the main factors in different time respectively. ${ }^{14}$ In previous studies, most researchers believe that the fluid activity is not the main factor that affect soil temperature, but their studies were taken in the period of May to September. However, the physiological metabolism of the plant is exuberant, and the soil temperature has little effect on sap flow activity. Therefore, the effect of soil temperature on the sap flow rate is ignored in the study. Soil moisture is the "source" of the sap flow activities within the plant tissue and soil temperature has an important influence on 
soil moisture. It determines the capacity of root water absorption and the effect root physiological activity. ${ }^{15}$ In short, although the soil temperature is not a direct factor affecting sap flow activity, it has an important influence on it. As the research of plant transpiration goes on, a large number of researchers have found that in cold conditions, soil temperature has obvious inhibitory effect on plant water utilization and physiological metabolism, which in turn affects the sap flow rate in plants. Schwarz and Kramer confirmed that the threshold temperature of soil temperature play a significant role on plant photosynthesis and transpiration is about $10^{\circ} \mathrm{C}$. Their studies shows the soil temperature section which has significant influence on flow activities is not near the freezing point, and that has something to do with the soil temperature that affect the energy state and effectiveness of water molecular. This reflects the indirect effect of soil temperature on the sap flow activities. ${ }^{16,17}$ Gao et al. ${ }^{18}$ found that when the soil temperature is lower than $12.585^{\circ} \mathrm{C}$, the viscosity of water is larger, the movement of water molecules is less efficient and fluid flow is slow. ${ }^{18}$ Junliang et al. ${ }^{19}$ measured the sap flow velocity of pinus tabulaeformis by adopting thermal diffusing flow probes and analyzed of main control effect of environmental factors on sap flow velocity in different seasons, meanwhile, the start time of fluid flow and the time to peak of sap flow velocity were also been determined. The results showed that the influence of low soil temperature $\left(10 \sim 14.9^{\circ} \mathrm{C}\right)$ on fluid activity was greater than other factors. ${ }^{19}$ Daoyong et al. ${ }^{20}$ set up the moisture migration and heat transfer coupling model in the process of soil moisture freezing. The study found that the temperature field has an important influence on water migration and the formation of ice crystals. The distribution of soil water content can be explained by the relationship between flow velocity and temperature. The correctness of the numerical results was verified by experiments. ${ }^{20}$ The above researches confirmed that soil temperature is the environmental factors that affects the plant sap flow rate, especially during soil freezing period in winter and soil unfreezing period in spring. Soil temperature plays a major role in controlling the sap flow rate in that time and the effect principle is: Soil temperature affects the water uptake activity of root cells and the hydraulic conductivity of the root system, which in turn affects the rate of fluid flow in plant tissues.

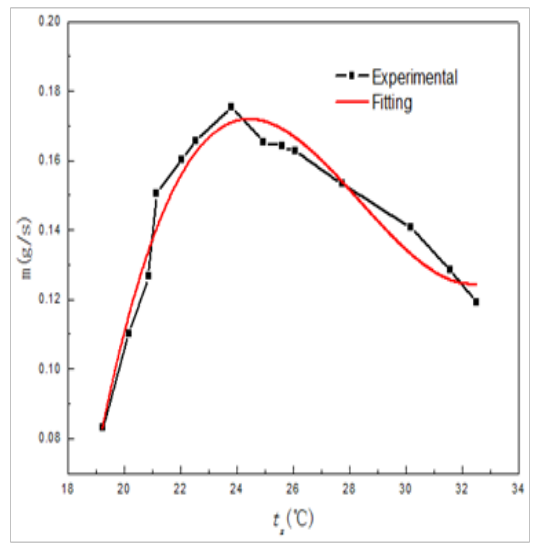

Figure 7 Variation of sap flow rate under different soil temperature.

The sap flow rate of Common Camellia stem varies with soil temperature was persistently measured from 12:00 to 15:00 during the fine weather from August 11 to 31, 2015 by changing the soil temperature around the root system. Table 2 shows all the experimental soil temperature. The corresponding sap flow rate of different soil temperature is plotted in Figure 7. In the whole range of soil temperature $\left(19.22 \sim 32.49^{\circ} \mathrm{C}\right)$, the sap flow rate has a "single peak" relationship with soil temperature. The sap flow rate increases rapidly with the increase of soil temperature when the temperature is in the range of $19.22 \sim 23.8^{\circ} \mathrm{C}$ and reaches the peak at $23.8^{\circ} \mathrm{C}$. Thereafter, the sap flow rate decreased with the increase of soil temperature. The optimum growth soil temperature of Common Camellia root is $21.14 \sim 27.71^{\circ} \mathrm{C}$, in the temperature range, with the increase of soil temperature, the viscosity of soil water decreases, the diffusion rate increases and the water absorption activity of root system increase. Therefore, the sap flow rate of root is higher. When the soil temperature is higher than the temperature interval, the enzyme in the root tissue cells will be passivity, the protoplasmic flow slows down and the water absorption capacity of the root system decreases. The calculation values of sap flow rate of Common Camellia stem in different soil temperatures were fitted, and the function relationship between them was obtained:

$\dot{m}_{\text {sap }} \propto-3.99+0.455 t_{s}-0.163 t_{s}^{2}+0.00019 t_{s}^{3} \quad\left(R^{2}=0.94\right)$

The formula (10) applicable to the soil temperature range of $19.22 \sim 32.49^{\circ} \mathrm{C}$.

Table 2 Soil temperatures

\begin{tabular}{lll}
\hline Time & $\begin{array}{l}\text { Temperature of the } \\
\text { water bath }\left({ }^{\circ} \mathrm{C}\right)\end{array}$ & Soil temperature $\left({ }^{\circ} \mathrm{C}\right)$ \\
\hline August $1 \mathrm{I}^{\text {th }}$ & No water & $27.7 \mathrm{I}$ \\
August $12^{\text {th }}$ & 22.0 & 23.50 \\
August $13^{\text {th }}$ & 19.0 & 22.03 \\
August $14^{\text {th }}$ & 17.0 & 20.85 \\
August $15^{\text {th }}$ & 17.8 & 21.14 \\
August $16^{\text {th }}$ & 22.3 & 22.54 \\
August $17^{\text {th }}$ & 17.5 & 19.22 \\
August $18^{\text {th }}$ & 25.2 & 20.16 \\
August $22^{\text {th }}$ & 26.6 & 24.93 \\
August $23^{\text {th }}$ & 29.7 & 26.06 \\
August $27^{\text {th }}$ & 27.8 & 25.59 \\
August $28^{\text {th }}$ & 32.5 & 30.15 \\
August $29^{\text {th }}$ & 36.2 & 31.55 \\
August3 $\left.\right|^{\text {st }}$ & 55.3 & 38.49 \\
\hline
\end{tabular}

It has been mentioned repeatedly that there are many parameters affecting the intensity of transpiration and the sap flow rate, such as net solar radiation intensity, air temperature, saturation deficit, stomata resistance, water potential distribution, wind speed, soil moisture, soil temperature, canopy structure and so on. But the influence of various parameters on the transpiration rate is different, even in very big difference. Among them, the illumination intensity, air temperature and soil temperature are three main factors that influence the sap flow rate. So it's very necessary to analyze the daily variation of sap flow rate with the three parameters by correlation analysis. However, the three parameters are interrelated and coupled for the actual plant physiology metabolic process. Therefore, the SPSS software was used to comprehensive analysis the effects of three parameters on sap flow rate by multivariate nonlinear function regression. SPSS is integrated computer data processing application software, which has many functions such as data entry, data editing, data management, statistical analysis, report making, graphics rendering and so on. Multivariate 
nonlinear function regression analysis was carried out to obtain the function expression between the sap flow rate and illumination intensity, soil temperature and air temperature.

$$
\dot{m}_{\text {sap }}=3.775(L)^{0.385}\left(t_{a}\right)^{0.554}\left(t_{s}\right)^{0.343} R^{2}=0.856
$$

Where, $L$ is the illumination intensity, lux. $t_{a}$ is air temperature ${ }^{\circ} \mathrm{C}$. $t_{s}$ is soil temperature ${ }^{\circ} \mathrm{C}$. The correlation result is similar to the research of Shao zhong Kang, who got the correlation between transpiration rate of winter wheat and net radiation, saturation difference and air temperature. ${ }^{21}$ This verifies the validity of the method. Although the sap flow rate was influenced by the three factors of illumination intensity, air temperature and soil temperature, the influence of each parameter on the sap flow rate is different. Order from high to low is the air temperature $(0.554)$, illumination intensity (0.338) and soil temperature (0.343). This is because the air temperature directly affects the opening of stomata on the leaf surface of the canopy. The increase of temperature increases the cell activity, stomata conductance and transpiration, this leads to an increase in sap flow rat.

\section{Experimental error analysis of sap flow rate}

A constant heat source is needed to determine the sap flow rate of Common Camellia stem by thermal equilibrium method. The temperature of Common Camellia stem was increased by annular heater which was wrapped outside the stem. When the temperature exceeds the range of its normal growth, the cell tissue will produce the HSP which induced by thermal stimulation. ${ }^{22}$ The HSP is widely distributed in the inner and outer regions of the cell structure and has thermal defense to cell tissue. That will affect the fluid flow. Furthermore, the flow resistance of the sap flow increases, resulting in a slightly less than the actual value.

\section{Results and discussion}

Firstly reviews the method of determination of plant transpiration and the heat method are finally selected to measure the sap flow rate of steam after considering the experimental requirements. An opentop artificial climate plant growth chamber was built to measure the sap flow rate of ten year old Common Camellia plant, without considering the influence of water stress on temperature distribution and sap flow rate in the experiment. In addition, the experiment was taken in summer with strong illumination intensity and transpiration. The relationship between sap flow rate of Common Camellia stem and illumination intensity, air temperature and soil temperature were eventual established. The SPSS software was used to comprehensive analysis the effects of three parameters on sap flow rate by multivariate nonlinear function regression.

\section{Conclusion}

a) The sap flow rate of Common Camellia has the same diurnal variation with illumination intensity and air temperature, but the time lag for about 1 3 hours. The sap flow rate in cloudy differs sharply with that in sunny, and the latter is twice the value of the former.

b) The sap flow rate of Common Camellia both has an exponential relationship with air temperature and illumination intensity in measurement range for the air temperature is relevant to illumination intensity. The flow rate increases sharply within certain limits, but fluctuates on a stable value beyond that.

c) The sap flow rate of Common Camellia in summer is about
$0.056-0.178 \mathrm{~g} / \mathrm{s}$. The results are consistent with Nie Lishui's research. That verifies the feasibility of the measurement method and the correctness of the measurement results.

d) In sunny weather, the sap flow rate increases with rising air temperature in 12:00 13:00 time period but decreases with the rising air temperature in 13:00-15:00 time period. That's all because the sap flow resistance increase in proportion and the transpiration rate decreased.

e) The sap flow rate has a "single peak" relationship with soil temperature within the temperature range for about $19.22 \sim 32.49^{\circ} \mathrm{C}$ and reaches the peak at $23.8^{\circ} \mathrm{C}$.

f) The main factors affecting the sap flow rate also changes with the continuous change of displacement in time and space. Soil temperature plays a major role in controlling the sap flow rate during soil freezing period in winter and soil unfreezing period in spring.

g) Although the sap flow rate was influenced by the three factors of illumination intensity, air temperature and soil temperature, the influence of each parameter on the sap flow rate is different. Order from high to low is the air temperature (0.554), illumination intensity (0.338) and soil temperature (0.343).

h) The measurement values of sap flow rate is slightly less than the actual, because the heat shock proteins has thermal defense to cell tissue. That will affect the fluid flow rate.

\section{Acknowledgement}

None.

\section{Conflict of interest}

Authors declare there is no conflict of interest.

\section{References}

1. Wiener N, Hao J. Cybernetics. USA: Science Publishing Company; 2009. p. $86-92$.

2. Deng D, Fan Z. Measurement and estimation of forest transpiration. Journal of ecology. 2008;27:1051-1058.

3. Grime VL, James IL, Simmonds LP. Including the heat storage term in sap flow measurements with the stem heat balance method. Agricultural and Forest Meteorology. 1995;74(1-2):1-25.

4. Wang HT, Luyi M. Measurement of whole tree's water consumption with thermal dissipation sap flow probe (TDP). Acta Phytoecologica Sinica 2002;26(6):661-667.

5. Kenciala E, Kucerab J, Malmer A. Tree sap flow and stand transpiration of two Acacia mangium plantations in Sabah, Borneo. Journal of Hydrology. 2000;236(1-2):109-122.

6. Clearwater MJ, Inzer FC, Andrade JL, et al. Potential errors in measurement of no uniform sap flow using heat dissipation probes. Tree Physiology. 2010;18(3):326-334.

7. Baker JM, Niber JL. An analysis of the steady-state balance method for measuring sap flow in plants. Agricultural and Forest Meteorology. 1989;48(1-2):93-109.

8. Cai X, Zhao P, Lu P, et al. The solution of common problems in A. Granier tree sap flow measurement system. Journal of tropical and subtropical plants. 2010;18:326-334

9. Luo Z, Zhang J. Fluid flow and transpiration rate of wheat. China determining method of agricultural meteorology. 1996;17(1):44-47. 
10. Liu A, Liu X, Lan H, et al. A Calibration of plant stem flow sensor based on thermal balance. Proceedings of the Chinese society of agricultural engineering. 2010;26(2):6-10.

11. Li S, Xiao L, Wang F, et al. Heat balance sap flow measuring accuracy and error analysis. China desert. 2014;34(6):1544-1551.

12. Xin X, Fan J, Li Q. Experimental Research on Physical Parameters inside Hardy-Plant Leaves. American Journal of Biological and Environmental Statistics. 2017;2(2):13-20.

13. Nie L, Li J. Application of TDP technology to study the liquid flow velocity of Pinus tabulaeformis. Journal of Beijing Forestry University. 2004;26(6):49-56.

14. Xu J, Ma L, Yan H. Sap flow process and the relationship between solar radiation and soil and water conservation Chinese. Science. 2006;4(2):103-107.

15. Xu J, Ma L. Soil temperature on Pinus tabulaeformis (Pinus tabulaeformis) affects the sap flow of activities. Journal of ecology. 2008;28(12):6107-6112.

16. Schwarz PA, Fahey TJ, Dawson TE. Seasonal air and soil temperature effects on photosynthesis in red spruce(Picea rubens) saplings. Tree Physiol. 1997;17(3):187-194.

17. Kramer PJ. Species differences with respect to water absorption at low soil temperatures. American Journal of Botany. 1942;29(10):828-832.

18. Gao PC, Zhang YP, Zhang H, et al. Influence of temperature on soil water character. Journal of Taiyuan University of Technology. 2004;35(4):385-387.

19. Xu J, Ma L, Yan H. Relationship between process of sap flow of Pinus tabulaeformis and solar radiation. Science of Soil and Water Conservation. 2006;4(2):103-107.

20. Wu D, Lai Y, Zhang M. Heat and mass transfer effects of ice growth mechanisms in a fully saturated soil. International Journal of Heat and Mass Transfer. 2015;86:699-709.

21. Kang S, Liu X, Xiong Y. Space water transmission theory and its application. China: Water Conservancy and electric power press; 1994. p. $9-15$.

22. Deng J, Duan B. The heat shock proteins of plant research and application. Agricultural research. 2003;23(3):226-228. 